Proc. 13th Econophysics Colloquium (EC) and 9th Symposium of Physics in Economy and Social Sciences (FENS), 2017

\title{
The Mechanism of Transformation of Global Business Cycles into Dynamics of Regional Real Estate Markets
}

\author{
A. JAKIMOWICZ ${ }^{a, *}$ AND S. KULESZA ${ }^{b}$ \\ ${ }^{a}$ Institute of Economics, Polish Academy of Sciences, Palace of Culture and Science, \\ pl. Defilad 1, PL-00-901 Warsaw, Poland \\ ${ }^{b}$ Faculty of Mathematics and Computer Science, University of Warmia and Mazury in Olsztyn, \\ Słoneczna 54, PL-10-710 Olsztyn, Poland
}

\begin{abstract}
The aim of this article is the identification of the occurrence mechanism of sudden quantitative changes in real-estate market prices, which were observed during the global financial crisis. Since such phenomena did not occur to such an intensity during previous crises, it can be assumed that a new economic dynamic type has emerged in real-estate markets. The most promising of the methods of studying such phenomena seems to be the bifurcation method and particularly the catastrophe theory. This study analyzes changes in the prices of residential property based on cusp catastrophes. Empirical data were fit to a stochastic cusp model to visualize the evolutionary path of real estate market. Two other popular models (linear and logistic) were also estimated to compare results. A comparative analysis proved that the cusp model can best explain structural price instabilities in real-estate markets. The results confirmed that the evolution of the real estate market combines two processes: long-term evolution in the area of non-degenerate stability and discontinuous changes in the area of degenerate stability. Structural changes take place in the system only in the area of degenerate stability. The theoretical and practical results show that the catastrophe theory may have predictive potential, which could support traditional methods of predicting changes on real estate markets.
\end{abstract}

DOI: $10.12693 /$ APhysPolA.133.1351

PACS/topics: housing price dynamics, structural transition, cusp catastrophe, critical point, bifurcation set, equilibrium surface

\section{Introduction}

The very essence of this paper lies in the diagnosis of dynamic phenomena in the real estate market during the global financial crisis. In mainstream economy dynamics of economic systems usually have been studied by focusing on stable equilibrium behavior with the assumption that the real estate market can generally exert positive influence on the economic stability and growth. In such assumption the dynamics of economic systems usually have been studied by focusing on stable equilibrium behavior. However, according to Schumpeter, the role of development analyses should be minimized in near-balanced systems, but highly accentuated in transition systems or systems that are far from equilibrium [1]. The above approach emphasizes the importance of qualitative changes in the development process. Qualitative changes are very difficult to describe in the form of a mathematical model. Systems which move from a nearbalanced state to a state that is far from equilibrium undergo significant transformations. Dynamical processes lead to evolution. In this case, evolution is the movement towards more complex states, and it is accompanied by structural changes [2]. The list of possible economic sources of complexity is quite extensive [3].

This paper introduces an transdisciplinary research program with the roots in the complexity in eco-

${ }^{*}$ corresponding author nomics $[4,5]$, whereby real estate markets could be seen as complex adaptive systems exhibiting properties specific of open, dynamic systems, which pays the special attention to the studies of transient phenomena, that is non-equilibrium states, turbulence, adaptive behavior, self-organization, etc. In this view, the real estate market is a special type of market with specific rules, and far from the definition given by mainstream economics.

The aim of the research presented here is to define a new type of dynamics in property markets which emerged during the global financial crisis which features two phases. The first phase includes a long-term and continuous system evolution along the equilibrium path, while the second phase concerns a short-term and discontinuous change of the trajectory, consisting of a sudden jump from one equilibrium path to another.

The choice of catastrophe theory as a research method was motivated both by practical and theoretical considerations. As the review of the economic literature shows, during a global financial crisis, changes in housing prices in various countries were synchronized and demonstrated a discontinuous nature. At the same time, sharp fluctuations in property prices, resembling jumps between two states of equilibrium, were also observed in Poland. Catastrophe theory provides a proper tool to describe such rapid changes. Therefore, a research hypothesis was posited that the causes for abrupt changes in property market prices in Poland should be attributed to changes in macroeconomic parameters caused by the global financial crisis, and that cusp catastrophe provides the tran- 
sition mechanism from the global to the local level. The choice of catastrophe theory was also motivated by theoretical reasons since, according to the classification theorem, all dynamic changes in low-dimensional space can be classified into a limited number of patterns which are referred to as elementary catastrophes [6].

We aimed at analyzing the quasi-discontinuous real estate price changes seen during the housing bubble and the following mortgage crisis using the tools of Thom's catastrophe theory. Although one of the elementary catastrophes - a cusp catastrophe - is sometimes used for modelling the housing prices [7-10], it has never been used for empirical verification of the transition mechanism from the global economy to the local real estate markets in Poland. Much empirical evidence has recently been gathered to prove that the global financial crisis, starting from its source to the results it produced in local property markets, followed a scenario consistent with a cusp catastrophe. If the same scheme is to repeat itself in local property markets, the asymmetry and bifurcation factors must be affected by macroeconomic variables. Thus, a cusp catastrophe transmits macroeconomic impulses from the global economy to local property markets. In other words, empirical research based on a cusp catastrophe indicates the following direction of the cause-and-effect relation:

subprime mortgage crisis [11] $\rightarrow$ global financial crisis $[12,13] \rightarrow$ global financial markets $[14,15] \rightarrow$ macroeconomic parameters $\rightarrow$ local property markets in individual countries [16-18].

Therefore, attaining the assumed objective requires broader empirical testing of the two latter links of this scheme for the Polish economy. In our article, we not only estimate the model based on the cusp catastrophe, but also compare the results to two other models - linear and logistic. It appears that the catastrophic model best matches reality. The significance of the method used in our research permits its application in research on housing markets in many countries all over the world.

\section{Real estate market, macroeconomic changes, and complexity in economics}

The real estate market can be defined at different levels of accuracy, subject to the purpose of the description, the applied criteria, the adopted reference standards and the required degree of precision. In its most abstract definition, real estate market is a complete system of entities (objects) with given attributes remaining under the influence of mutual interactions that modify the status of a property (buying, selling, renting). The real estate market is the basis for transactions concerning the buying and selling of land, buildings, houses, etc., hence operating at the intersection of mutually related areas of law, economic, social and political activities [19-21]. Real estate market has roots in current microeconomic and macroeconomic reality, but is additionally subjected to a large variety of external stimuli. Observed interactions may differ in their direction and intensity, and the real estate market in which they can act either as a sender or receiver of those stimuli. For example, Tobin and Montz [22] analyzed catastrophic flooding and the response of the real estate market. According to Foryś [23], the property market together with its economic and social environment form a system of communicating vessels such that stagnation in one of the segments and lack of communication between the sectors have a negative impact on the remaining elements of the system.

Macroeconomic equilibrium is determined by powerful relations between the real estate market and the national economy. The above is particularly visible in the relations between the housing sector and the financial market. The situation on international financial markets affects property prices in many countries [24]. It could be assumed that vast fluctuations in real estate prices observed in the past decade are not merely transitional adjustments for long-term global trends. Such effects on the dynamics of the Asian real estate market were analyzed by Gerlach et al. [25]. Quigley [26] investigated the relations between economic cycles and property prices, whereas Sornette and Woodard [27] examined the origins of the financial crisis and described the resulting sudden drop in real estate prices.

In the traditional approach, the property market is a factor contributing to increased economic stability and growth. It performs those functions by contributing to the gross domestic product, catering to the demand for housing, creating new jobs, contributing revenue streams from local property taxes, effectively allocating land resources and supporting the reinvestment of capital through the mortgage system. A strong reverse relationship is also observed: changes in economic policy, in particular monetary policy, evoke a response from the real estate market. According to the European Central Bank [28], changes in interest rates affect property prices, and the economic situation in the housing sector (increase in the housing development and modernization projects), cost and availability of loans (for households and businesses), thus leading to a decrease or increase in consumer demand.

The authors suggest that the strong fluctuations in the real estate prices observed, in the last decade, in many countries are not just disruptions of trends or cycles but are an essential part of the market, which - destabilized by changes in the macroeconomic situation - seeks a new state of equilibrium through quasi-discrete changes in prices. For example, in Poland, the real estate prices rose steadily between 1990 and 2003, subject to periodic variations. Such a trend and its length and stability pointed to a certain security and stabilization. It was not until 2004 (when Poland entered the European Union, which, in turn, resulted in easy access to low-cost capital) that the real estate prices started to fluctuate rapidly - such a situation was especially visible from 2006 to 2007 and undermined the belief in real estate market stability. The recent real estate market dynamics and the accompanying changes in the real estate prices 
were very intense, multi-phased and, in some periods, could be interpreted as market instability.

The real estate market can be analyzed in terms of a set of its constituent elements (objects - property, agents - market participants), the relations between those elements (e.g. transfer of property, real estate taxes) and specific attributes of those elements (type of property, location). By sending signals to the environment and receiving stimulatory feedback, the real estate market undergoes structural transformation over time, and the trajectory of its evolution changes in state space. Real estate markets thus fulfill the definition of a complex adaptive system proposed by Gell-Mann [29]. This means the possibility of studying them using nonlinear dynamics methods and applying catastrophe theory.

If the system's sensitivity threshold to external stimuli is exceeded, it becomes unstable and moves from a nearly stable state to a state that is far from equilibrium. These dynamical processes often induce key changes in the system's trajectory of evolution in state space, leading to the transformation of one form into another in the process of discontinuous and discrete changes in the system's state. In economic theory, such changes are referred to as discrete growth which, according to Jakimowicz [30] implies changes that put the economy (or its sectors) on a different path of growth or recession. Cieślak and Smoluk [31] have argued that discontinuity occurs because an unstable system aims to achieve a new stable state and discontinuity somewhat alleviates tension in the system.

Attempts to define stability and instability were made already in the 19th century by Maxwell who observed: "When the state of things is such that an infinitely small variation of the present state will alter only by an infinitely small quantity the state at some future time, the condition of the system, whether at rest or in motion, is said to be stable; but when an infinitely small variation in the present state may bring about a finite difference in the state of the system in a finite time, the condition of the system is said to be unstable" [32]. According to Arrow [33], the stability of a system implies the existence of an attribute which guarantees that when the system leaves equilibrium, a self-regulatory mechanism will be initiated to bring the system back to the path of equilibrium. Instability is a transitional stage between two states of systemic equilibrium: the existing state and the new (target) state.

In this study, an attempt was made to determine whether phenomena characteristic of structurally unstable markets which, under the influence of a finitely small number of control parameters, experience discontinuous changes in their state can be observed in surveys of the real estate market. The instability of property markets should be analyzed considering changes in the principle state variable, namely, the price of property which changes far less rapidly than the prices on other markets, such as the stock market.

The fundamental assumption in this paper is that the real estate market is a dynamic system evolving toward its equilibrium state, for which intervals of sudden price change establish critical points on the evolution path. Critical points mark structural transitions within a system between a current development scheme with vanishing perspectives for further growth and a new one with a number of prospective alternatives. In this case, due to fluctuations of independent variables, the real estate market only periodically enters into a state of instability, in the process of searching for a new state of stability.

\section{Catastrophe theory}

The perception of catastrophe theory in science involves a certain paradox. On one hand, it appears to have been known for long, while on the other, it is not usually attached the importance it deserves. To elucidate the problem, it was decided to present catastrophe theory in more detail. It has a significant importance in science, since it reduces all system evolution scenarios available in the real world to eleven patterns - elementary catastrophes - if the space dimension is not higher than five [34]. In numerous econophysics conferences, researchers have presented results which are often low-dimensional cross-sections of forms corresponding to the elementary catastrophes. In such cases, catastrophe theory permits identifying a more general pattern of dynamics, and consequently, to gain a deeper insight into the entirety of the examined phenomenon.

In the catastrophe theory, terms "crisis", and "catastrophe" are substantially different taking into account their functional meaning. According to Thom [35], a crisis precipitates the catastrophe, acts as a forerunner of it and sometimes it might even trigger the catastrophe. In such a sense, Thom defined the catastrophe as an observed discontinuity, whereas the crisis appears to be a hidden phenomenon [36]. Hence, catastrophe can be understood in terms of loss of stability of the system that leads to a new, stable state emerging from the state space [37]. If so, catastrophe theory aims to determine, how the object of study (system, process) behaves over time, how it reacts to external stimulation, how it evolves within instability intervals and how the continuous causes give rise to discontinuous changes.

Catastrophe theory has become a subject of increased research interest in various areas of knowledge. Below the authors provided only several selected examples. In the field of biological sciences, this theory was used by Cobb and Zacks [38]. Phenomena occurring in urban spaces were analyzed by Casti and Swain [39], Amson [40], and Wilson [41], topics in behavioral sciences were studied by Sussmann and Zahler [42], Guastello [43], and Hartelman et al. [44]; in chemistry it was used by Okniński [37] and Wales [45] and in physics - by Fuhua and Huanmin [46]. A number of applications of the catastrophe theory in the economic sciences were reported by Zeeman $[47,48]$, Rosser [49, 50], Barunik and Vosvrda [14], Barunik and Kukacka [15], Jakimowicz [51], Dou and Ghose [52], and Varian [53]. 
Cobb and Watson [54] made a significant contribution to statistical procedure for analyzing catastrophe models through nonlinear regression while Hartelman [55], and Grasman et al. [56] rebuild Cobb's [57] procedure in the $\mathrm{R}$ program language which software was used throughout this study [58].

According to catastrophe theory, in four-dimensional space-time all structural changes which can take place proceed according to one of seven patterns, which are called elementary catastrophes. The basis of catastrophe theory is the classification theorem, according to which all structural changes to any objects can only take place according to a strictly-determined and finite number of patterns, named elementary catastrophes. The proof of this theorem was given by Trotman and Zeeman [59]. There are seven elementary catastrophes in four-dimensional space-time: fold, cusp, swallowtail, butterfly, hyperbolic umbilic, elliptic umbilic, parabolic umbilic. They are represented with simple polynomials. Relatively simple models are thus obtained, which can generate extremely complex dynamics. This is where the usefulness and universality of this method lies.

A catastrophe means a sudden, discontinuous qualitative change which moves the analyzed system from one set of differential equations to another. This phenomenon could have a positive or negative transformation direction. The rate of changes in the object's behavior compared to the mean change in the past should be taken into consideration. Catastrophe theory combines many seemingly contradictory and unconnected methods of describing phenomena into one coherent notional system: evolutionism and revolutionism, continuity and discontinuity, stationarity and non-stationarity. The applications of catastrophe theory in economics are of great cognitive importance, as Rosser [60] points out, they were what initiated complexity economics.

Catastrophe theory concerns systems immersed in a potential field. The term "potential" (or alternatively "potential function") is a key to this theory, as it entirely determines both behavior and stability of the system. In general, the potential takes the form

$$
V(\boldsymbol{x}, \boldsymbol{c})=V\left[\left(x_{1}, \ldots, x_{n}\right),\left(c_{1}, \ldots, c_{k}\right)\right],
$$

where $\left(x_{1}, \ldots, x_{n}\right)$ describe system state variables, while $\left(c_{1}, \ldots, c_{k}\right)$ describe control parameters. As mentioned previously, systems considered in this study always evolve toward a state of permanent stability being pushed there by potential forces (force-feedback):

$$
f_{i}=-\frac{\partial V(\boldsymbol{x}, \boldsymbol{c})}{\partial x_{i}}, \quad i=1, \ldots, n .
$$

This balancing process takes place until a stationary state is reached in which all state variables remain constant over time

$$
\frac{\partial x_{i}}{\partial t}=0, \quad i=1, \ldots, n .
$$

In a stationary state, the first partial derivatives are all equal to zero and, hence, the potential forces vanish as well

$$
\frac{\partial V(\boldsymbol{x}, \boldsymbol{c})}{\partial x_{i}}=0, \quad i=1, \ldots, n .
$$

The roots of Eq. (4) are referred to as critical points of the system and they form a system equilibrium surface $M$ that obeys the following equation:

$$
M=\left\{(\boldsymbol{x}, \boldsymbol{c}) ; \frac{\partial x_{i}}{\partial t}=-\frac{\partial V(\boldsymbol{x}, \boldsymbol{c})}{\partial x_{i}} ; i=1, \ldots, n\right\} .
$$

As mentioned previously, since the system behavior is fully determined by the potential function, the overall characteristics of the potential need to be studied. However, one should make a distinction between two extreme cases

$$
\begin{aligned}
& \Omega=\left\{(\boldsymbol{x}, \boldsymbol{c}), \frac{\partial V}{\partial x_{i}}=0, \frac{\partial^{2} V}{\partial x_{i}^{2}} \neq 0, i=1, \ldots, n\right\}, \\
& \Sigma=\left\{(\boldsymbol{x}, \boldsymbol{c}), \frac{\partial V}{\partial x_{i}}=0, \frac{\partial^{2} V}{\partial x_{i}^{2}}=0, i=1, \ldots, n\right\} .
\end{aligned}
$$

Equation (6) establishes a set $\Omega$ containing nondegenerate equilibrium states, while Eq. (7) defines a set $\Sigma$ consisting of degenerate equilibrium states. Nonempty $\Sigma$ set is a pre-requisite for the catastrophes, since structural instabilities require degenerate equilibrium states to occur. On the other hand, potential systems with non-degenerate critical points are always structurally stable. As seen, the sum of two sets: $\Omega$ and $\Sigma$, is the equilibrium surface $M$. In turn, projection of $\Sigma$ onto a space of control parameters defines bifurcation set $B$ providing the structural instability of the system.

If the conditions for stationary equilibria are fulfilled, the system can be studied using elementary (static) catastrophe theory, which best describes qualitative (discontinuous) changes within the system caused by continuous change in control parameters. Among others, of particular interest for models of the dynamics of real estate market is a cusp catastrophe, defined using only one state variable $x$, and two control variables $\alpha$ and $\beta$ called normal and splitting factors or asymmetry and bifurcation factors, respectively

$$
V(\boldsymbol{x}, \boldsymbol{c}) \equiv V[x,(\alpha, \beta)]
$$

Both control variables are simultaneously canonical variables, which mean that they are built as linear combinations of independent variables

$$
\begin{aligned}
& \alpha=\alpha_{0}+\sum_{i=1}^{n} \alpha_{i} x_{i}, \\
& \beta=\beta_{0}+\sum_{i=1}^{n} \beta_{i} x_{i} .
\end{aligned}
$$

Several independent variables were joined together to form the asymmetry factor and bifurcation factor and these canonical variables were then analyzed to obtain the best possible fit.

A potential function in a cusp catastrophe is given in the form

$$
V: \mathrm{R}^{2} \times \mathrm{R}^{1} \rightarrow \mathrm{R} .
$$

The simplest mathematical structure which can fully represent all cusp catastrophe characteristics is a polynomial 
structure with the form

$$
V(x, \alpha, \beta)=\frac{1}{4} x^{4}+\frac{1}{2} \beta x^{2}+\alpha x .
$$

The $1 / 4$ and $1 / 2$ coefficients were selected so as to simplify discussion. Thus, Eq. (12) represents the basic model used in this paper to study price changes on real estate markets.

Equilibrium surface $M$ (set of critical points) contains roots of the equation

$$
M=\left\{(x, \alpha, \beta) ; \frac{\partial V}{\partial x}=x^{3}+\beta x+\alpha=0\right\} .
$$

The subset of degenerate equilibrium states $\Sigma$ is given by

$$
\Sigma=M \cap\left\{(x, \alpha, \beta) ; \frac{\partial^{2} V}{\partial x^{2}}=3 x^{2}+\beta=0\right\} .
$$

Bifurcation set $B$ consists of control parameters which fulfill the condition

$$
B=\left\{(\alpha, \beta) ; 4 \beta^{3}+27 \alpha^{2} \leq 0\right\} .
$$

On the whole, the evolution path of the system can be thought of as a curve in state space, driven straight onto the equilibrium surface or in the nearby space.

A cusp is one of the simplest elementary catastrophes. The shape of the equilibrium surface of the cusp catastrophe - shown in Fig. 1 - is formed by the set of all extrema of the probability function defining the probability distribution of variable $x$. The upper and lower sheets in the behavior plane $M$ determine the set of all state variable distribution maxima and its middle layer - the set of minima. This results from the fact that the most probable states are analyzed.

As Fig. 1 shows, when Eq. (12) has three different real roots $\left(D=4 \beta^{3}+27 \alpha^{2}<0\right)$, there are two locally stable conflict regions on the catastrophe surface $M$. The system cannot be in both places at the same time (i.e. simultaneously on the upper and lower sheets of the equilibrium surface) and this means that a choice should somehow be made between the stable regions to precisely define the points at which the catastrophe is taking place. One of two heuristic conventions are most often adopted to achieve uniqueness: the perfect delay convention or the Maxwell convention. According to the perfect delay convention, when the system's trajectory runs on a specific equilibrium surface, the catastrophe (structural change) appears at the moment when one of the layers of this surface ends and the next appears. With the Maxwell convention, the state of the system is indicated by the absolute maximum of the probability distribution function.

The probability distribution function $P_{\xi}(x)$, which implies the shape of the equilibrium plane characteristic of the cusp catastrophe, can be written as follows:

$$
P_{\xi}(x)=\left[\frac{x^{4}}{4}+\frac{\alpha x^{2}}{2}+\beta x+g(\xi)\right]^{-1},
$$

where $\xi=(\alpha, \beta)$ and $g$ is the only function of variable $\xi$ such that for each $\xi$ the expression in square brackets is positive and it is true that

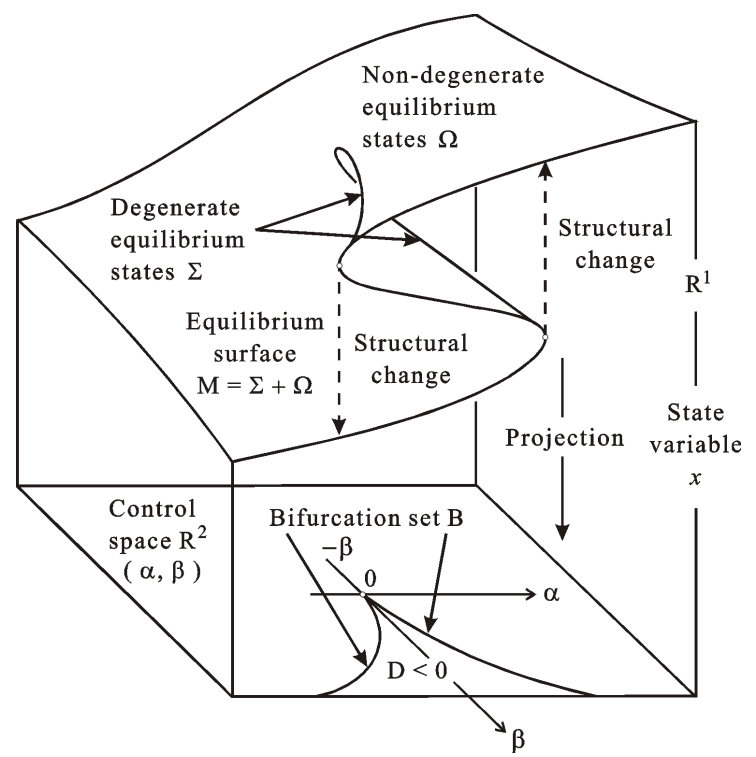

Fig. 1. Geometric interpretation of the cusp catastrophe. Structural changes take place according to the perfect delay convention.

$$
\int_{-\infty}^{\infty} P_{\xi}(x) \mathrm{d} x=1 .
$$

Figure 2 shows an example evolution of state variable probability distribution in time. At the moment $t_{0}$ we have a distribution with a single maximum at point $x_{0}$ corresponding to movement along the upper edge of the equilibrium surface, which occurs for $\beta_{0}$ (Fig. 1). The appearance of the bifurcation factor $\left(\beta_{0}\right)$ causes the emergence of two competing maxima at points $x_{1}$ and $x_{2}$, which corresponds to the formation of a fold in the behavior plane. A catastrophe means a jump of the system from a less to more probable situation, i.e. from point $x_{1}$ to $x_{2}$ at the instant $t_{1}$ or from $x_{2}$ to $x_{1}$ at the moment $t_{2}$. The Maxwell convention applies here, due to which the system tends toward the absolute maximum of probability distribution. If a perfect delay convention were adopted, the jump would occur only after the disappearance of one of the local maxima.

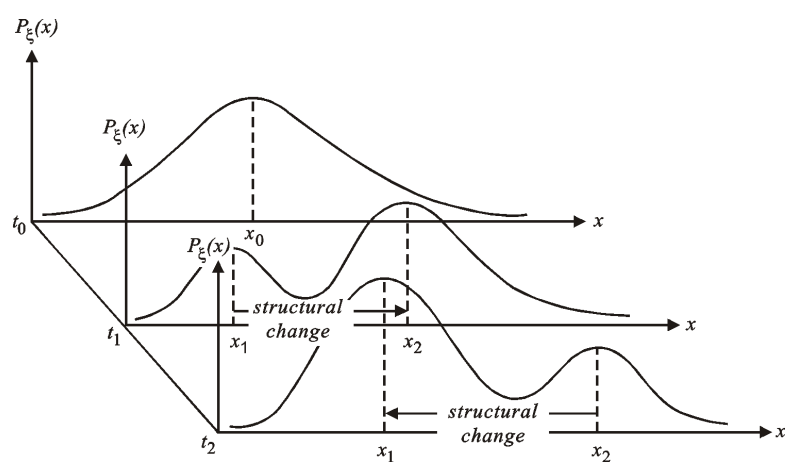

Fig. 2. State variable probability distributions for the cusp catastrophe. 


\section{The data source \\ for real estate market research}

The evolution of equilibrium states on the real estate market was analyzed based on the example of local housing markets (dwellings) in Poland. The selection of markets was determined by the availability of data, but the proposed methodology can be applied to every local market operating in line with free-market principles. The study was carried out in the cities of Poznan and Olsztyn, which vary considerably in size, their significance for the national economy, income levels, and property prices. The key statistical data of the analyzed cities are presented in Table I.

TABLE I

Statistical data for cities Poznań and Olsztyn.

\begin{tabular}{c|c|c|c|c}
\hline \hline City & Region & $\begin{array}{c}\text { Area } \\
{\left[\mathrm{km}^{2}\right]}\end{array}$ & Population & $\begin{array}{c}\text { Population } \\
\text { density } \\
{\left[\text { people } / \mathrm{km}^{2}\right]}\end{array}$ \\
\hline Poznań & Wielkopolska & 261.91 & 551627 & 2106 \\
\hline Olsztyn & $\begin{array}{c}\text { Warmia } \\
\text { and Mazury }\end{array}$ & 88.33 & 175420 & 1986
\end{tabular}

The Registry of Prices and Values maintained by the City Administration Office was the source of data relating to 12,000 property transactions (dwellings) in Poznań and 9,000 property transactions (dwellings) in Olsztyn. Change trends in real estate prices were analyzed for the period between January 2001 and October 2011. The distribution of property prices per square meter in Poznań and Olsztyn is presented in Fig. 3.

The graphic representation of the distribution of property prices in Poznań and Olsztyn in Fig. 3 points to a high level of proportionality between the directions and dynamics of the trends on the analyzed markets. Regardless of the initial differences in price levels in 2001, the examined markets responded nearly identically to changes in the market environment and they underwent similar transformations in time and value. It can be assumed that local factors were not the cause of sudden price fluctuations from the middle of 2006 until the middle of 2007 in Poznań, or from 2007 till the beginning of 2008 in Olsztyn, but were rather determinants of the rankings of these local markets in the national hierarchy.

The distribution of property prices in Poznań and Olsztyn also indicates that the largest increase in property prices occurred in both cities in 2007 at the monthly rate of approximately 10\%, when the highest differences between maximum and minimum prices was observed in a given time interval. The difference reached around PLN 6,000 (EUR 1,430) in Poznań and around PLN 4,500 (EUR 1,070) in Olsztyn. This behavior could be indicative of the examined markets' instability in 2007, which results from attempts to reach equilibrium following changes in its environment and the search for new paths of evolution in the process of sudden price changes.

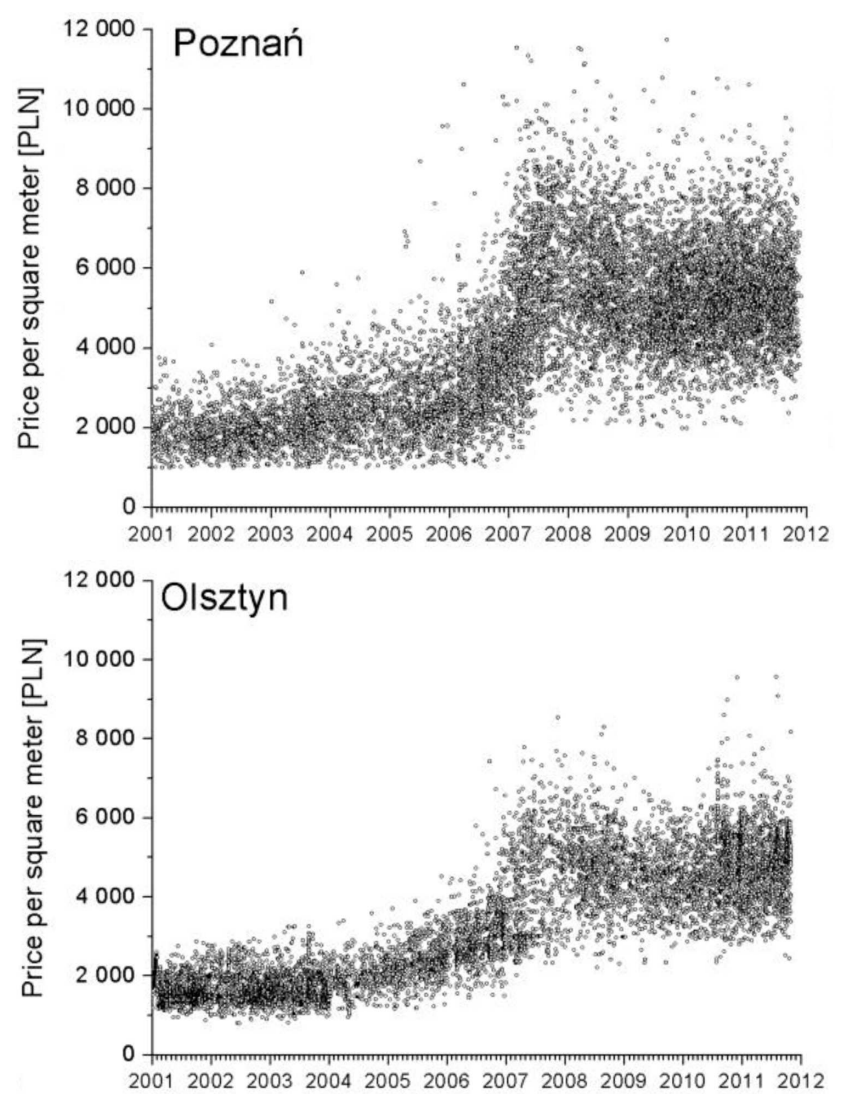

Fig. 3. Transactional property prices per square meter in Poznań and Olsztyn (January 2001 to October 2011).

In 2001-2006, the increase in property prices in Poznań and Olsztyn was slow and stable and it was during this period that the smallest differences between maximum and minimum prices were noted at around PLN 2,000 (EUR 480) in Poznań and PLN 1,500 (EUR 360) in Olsztyn. Following a steep increase in prices, the property market gradually stabilized during a gently downward trend in 2008-2011 when a considerable difference between maximum and minimum prices was reported at around PLN 4,000 (EUR 950) in Poznań and PLN 3,500 (EUR 830) in Olsztyn. The graphic representation of the distribution of property prices in the analyzed cities supports the observation that a sudden increase in prices should be regarded as a critical point in the evolution of the studied markets.

The applicability of the catastrophe theory to the real estate market is also justified by the multimodal nature of empirical data, namely, the presence of at least two states of stable equilibrium in the system. The distribution of residential property prices in Poznań and Olsztyn is presented in Fig. 4.

The distribution of the prices of residential property per square meter, covering 12,000 transactions in Poznań and 9,000 transactions in Olsztyn, has a bimodal character. This means that two paths of evolution on the equilibrium surface can be assigned to a given set of control parameters. In strongly bimodal systems, the 

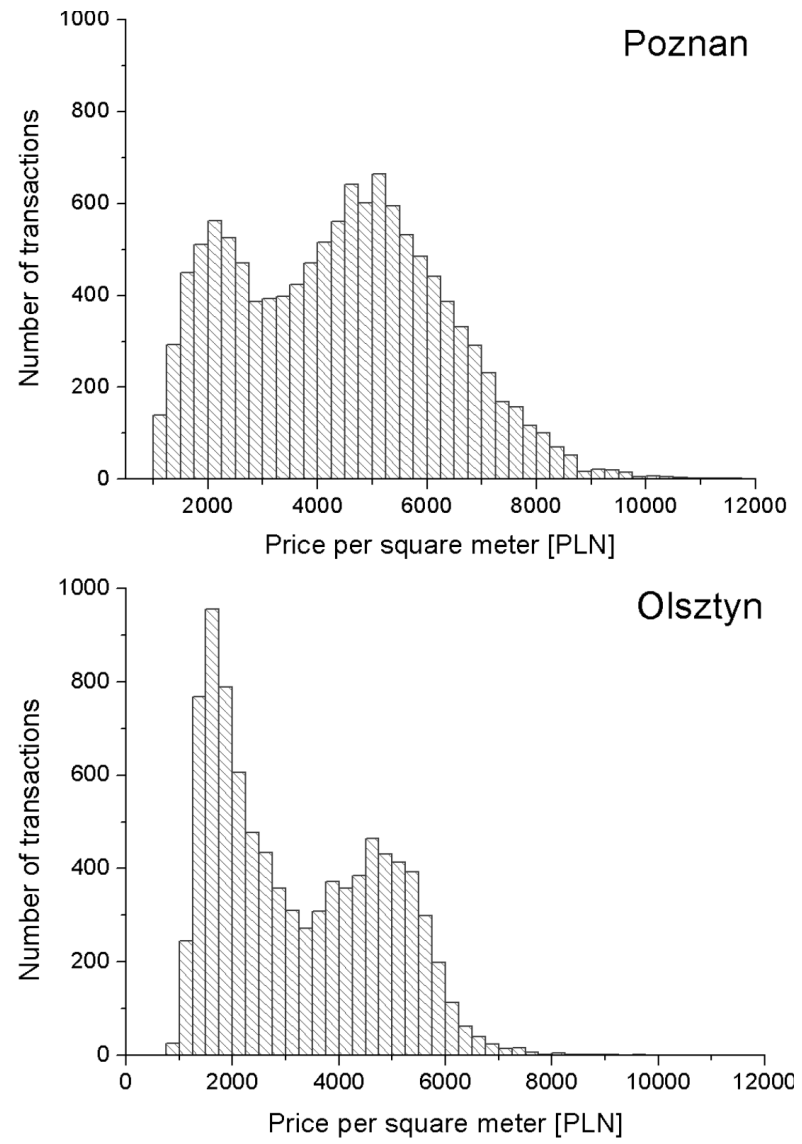

Fig. 4. Histograms of property prices per square meter in Poznań and Olsztyn (January 2001 to October 2011).

evolutionary path can take the shape of a hysteresis loop which moves between the allowed states of equilibrium; alternatively, it can be split into two paths that evolve more or less independently. In a real system, this would imply a rapid increase and a rapid decrease in property prices. The prices could be strongly differentiated to account for the specific attributes of real estate and the prices in one property group would evolve differently from other groups (e.g. minor changes in the prices of highstandard property with strong simultaneous fluctuations in the prices of standard property).

The statistical interpretation of bimodal distributions in Fig. 4 could confirm that on the analyzed markets in Poznań and Olsztyn, one trajectory of evolution was replaced by another in the process of price fluctuations. It implies that the distribution of empirical data shown in Fig. 4 illustrates two completely different states of equilibrium which are separated by an unstable state.

\section{The cusp catastrophe model}

The cusp model was developed according to formula (12) by determining the variable of state $(x)$ and independent variables in the set of control parameters: the asymmetry coefficient $(\alpha)$ and the bifurcation coefficient $(\beta)$.
The property prices, the rate of price changes and changing trends reflect various factors and processes on the real estate market and in the market environment. Therefore, property prices are robust indicators of the situation on the property market. Other parameters are also used to describe the state of the market, including the value of property, rental prices, return rates and the house price index, but most surveys rely on average transaction prices. The empirical data shown in Fig. 3 were used to calculate average transaction prices per square meter of residential property in Poznań and Olsztyn. Transaction prices were applied as state variables $(x)$ in follow-up calculations. These prices were corrected by the inflation rate.

The development of the property market, particularly the housing market, is correlated with economic growth. For this reason, one control variable was built based on the key measure of national income - the gross domestic product (GDP). For the property market to develop, investors need ample access to financing sources. Changes in mortgage rates are a reflection of the country's macroeconomic situation and interest rates set by the central bank. In this study, control variables were developed in view of the average interest rate of the central national bank (ARN) which comprises the reference rate, the lombard rate and the rediscount rate. Unemployment rate (UR) and the number of new dwellings (NND) were also regarded as important factors. The housing market situation is a reflection of the financial situation of households which is determined by their income levels. The probability of investments on the real estate market increases with income. High unemployment lowers the demand for housing and increases mortgage default risk. The last independent variable in the set of control parameters was the number of property transactions (NT). Data regarding the analyzed variables were acquired from the Central Statistical Office (GDP, UR and NND), the National Bank of Poland (ARN) and the database of property prices in Poznań and Olsztyn (NT). For the control variables GDP and ARN, their real values were taken into consideration.

\section{Testing the cusp model on the real estate markets}

Numerical fits presented in this paper were made using an advanced computation package "cusp" first described in an article by Grasman et al. as an add-on for the statistical computing language $\mathrm{R}$ [56] and recently updated by R. Grasman in 2015. The package was downloaded from the Comprehensive R Archive Network [61]. The package implements Cobb's maximum likelihood algorithm [38] and offers a number of specialized routines that help comprehensive fitting of cusp catastrophe models to given data series: from data plotting and fitting various models (linear, logistic, catastrophic) to comparing fit quality measures.

The analysis was performed with the use of Hartelman's cuspfit software $[55,58]$ which evaluates the qual- 
ity of cusp model fit to empirical data by comparing the results for a linear model and a logistic model. The following metrics were used to evaluate the fit quality: coefficient of determination $R^{2}$ (only for linear and the logistic models), pseudo- $R^{2}$ (only for the cusp model), logLik (likelihood ratio test), AIC (Akaike information criterion) and $\mathrm{BIC}$ (Bayesian information criterion). Unlike the determination coefficient $R^{2}$ which always assumes positive values, pseudo- $R^{2}$ can take on both positive and negative values, and it is calculated according to the following formula [57]:

$$
R^{2}=1-\frac{\operatorname{Var}(\Delta)}{\operatorname{Var}(y)}
$$

where $\operatorname{Var}(\Delta)$ is the variance of differences between the observed values and the maximum values of probability distribution which are closest to the observed values and $\operatorname{Var}(y)$ is the variance of state variable. The higher the value of logLik, the better the model's fit to the data, whereas a better fit is achieved at lower values of AIC and BIC.

In the first stage of the study, all independent variables presented in previous section were regarded as significant. Linear combinations of independent variables determine canonical control parameters of the analyzed system and, in line with formula (8), they were expressed as $\alpha$ (asymmetry coefficient) and $\beta$ (bifurcation coefficient). The above assumption was verified by fitting the model to the data, and the significance of independent variables was determined in the following order for the asymmetry coefficient $(\alpha)$ : GDP, ARN, UR, and for the bifurcation coefficient $(\beta)$ : NT and NND. The final fit of selected independent variables to empirical data describing local markets in Poznań and Olsztyn in 2001-2011 is presented in Tables II and III.

The fitted parameters presented in Tables II and III indicate that the behavior of real estate markets is more effectively described by catastrophe theory and the cusp model than other models (linear, logistic). Significantly, different property markets in Poznań and Olsztyn were also found to respond similarly to environmental stimuli.

\section{TABLE II}

Values of fitted parameters and the quality of fit of cusp, linear and logistic models to empirical data for Poznań in 2001-2011.

\begin{tabular}{l|c|c|c|c}
\hline \hline \multicolumn{1}{c|}{ Model } & $R^{2}$ & logLik & AIC & BIC \\
\hline Linear & 0.95 & -944 & 1904 & 1926 \\
Logistic & 0.98 & -868 & 1766 & 1770 \\
Morphogenetic & 0.99 & 110 & -189 & -184 \\
\hline & \multicolumn{2}{|c}{ Asymmetry } & \multicolumn{2}{c}{ Bifurcation } \\
& factor $(\alpha)$ & \multicolumn{2}{c}{ factor $(\beta)$} \\
\hline INTERCEPT & \multicolumn{2}{|c}{81.900} \\
GDP & \multicolumn{2}{|c}{0.760} & \multicolumn{2}{|}{} \\
ARN & \multicolumn{2}{|c}{-0.810} & -0.023 \\
UR & -1.896 & & \\
NT & & &
\end{tabular}

TABLE III

Values of fitted parameters and the quality of fit of cusp, linear and logistic models to empirical data for Olsztyn in $2001-2011$.

\begin{tabular}{l|c|c|c|c}
\hline \hline \multicolumn{1}{c|}{ Model } & $R^{2}$ & logLik & AIC & BIC \\
\hline Linear & 0.95 & -917 & 1851 & 1874 \\
Logistic & 0.98 & -859 & 1748 & 1791 \\
Morphogenetic & 0.98 & 78 & -125 & -79 \\
\hline & \multicolumn{2}{|c}{ Asymmetry } & \multicolumn{2}{c}{ Bifurcation } \\
& factor $(\alpha)$ & \multicolumn{2}{c}{ factor $(\beta)$} \\
\hline INTERCEPT & \multicolumn{2}{|c}{-63.660} \\
GDP & \multicolumn{2}{|c}{-0.116} & \multicolumn{2}{|}{} \\
ARN & -0.136 & \\
UR & -1.285 & & 0.031 \\
NT & & &
\end{tabular}

A comparison of pseudo- $R^{2}$ values (0.99 for Poznań and 0.98 for Olsztyn) for the cusp model and $R^{2}$ values for logistic (0.98) and linear (0.95) models reveals an advantage of the cusp model. More reliable results are produced when the remaining parameters are included in the comparison. The values of fitted parameters in linear and logistic models are somewhat different. They are significantly worse than those noted in the cusp model, which gives further evidence of the cusp model's superiority over the remaining models.

The results presented in Tables II and III validate the assumption that sudden fluctuations in property prices can be defined as critical points in a market's evolution rather than mere adjustments for its long-term trends. During those periods, the trajectory of a market's evolutionary path is changed. The previous path of development cannot be continued and an alternative trajectory of evolution has to be found. The evolutionary paths of both analyzed property markets in the space of control parameters $\alpha$ and $\beta$ are represented graphically in Fig. 5 .

If we account for minor differences in the range of coordinate axes, both paths appear to be similar. The initial, small variations in property prices place the start point of each path in the area of structural stability in the lower right quarter of the chart (set $\Omega$ of non-degenerate equilibrium states). A high concentration of trajectory points in this area corresponds to minor fluctuations in state variables (a small difference between maximum and minimum prices in a given time interval). Evolutionary paths then move toward the pointed tip where they enter the area of structural instability (set $\Sigma$ of degenerate equilibrium states). This point illustrates the catastrophe discussed at the beginning of this article, namely, a sudden (within a time scale characteristic of the real estate market) change in the state of a system which leads to a rapid increase in property prices. The path of evolution enters the area of structural instability relatively deeply (upper left quarter of the chart) and, as an equally characteristic feature, those sudden changes are accompanied by the path's rapid progression into the system's 

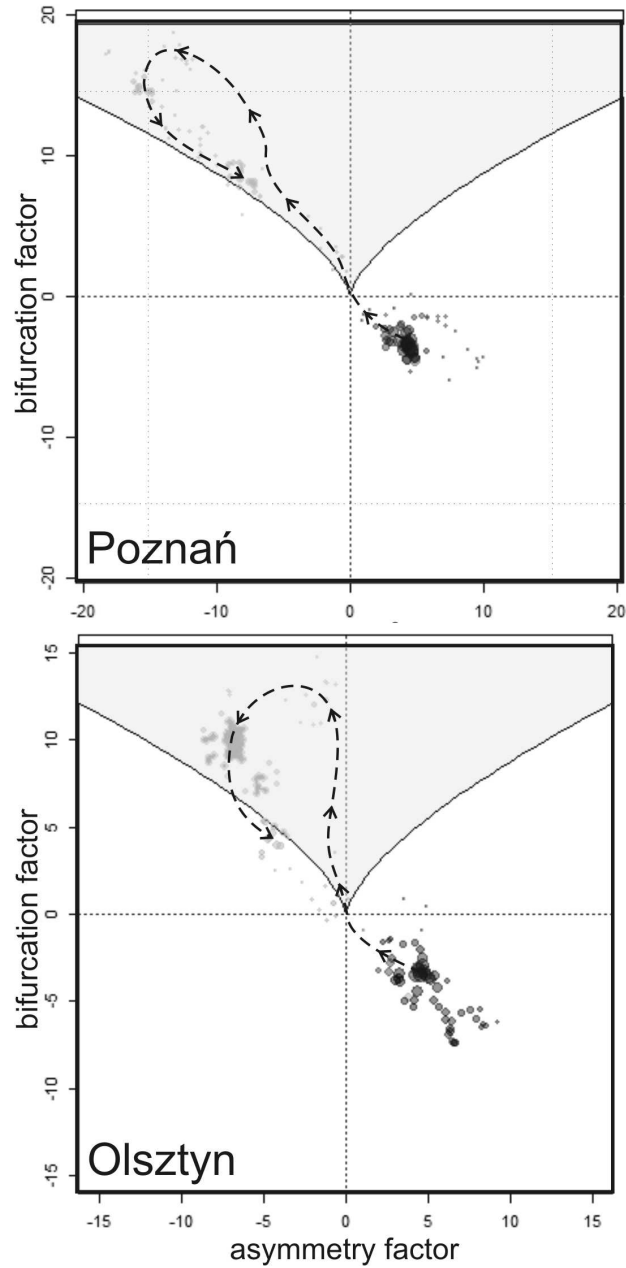

Fig. 5. Two-dimensional projection of the evolutionary path in the phase space of the system in Poznan and Olsztyn.

phase space. A small cluster of points in the area of the pointed tip and on top of the crease also indicates greater variation in prices. The only difference between the studied systems is expressed by the intensity of changes. In Olsztyn, the evolutionary path penetrates the instability area more deeply because values of the asymmetry coefficient (parameter $\alpha$ ) are closer to zero. Toward the end of the analyzed period (October 2011), both paths once again approached the edge of the instability area. This could imply that after a period of rapid price changes in 2007 and a stable drop in prices in successive years, the system made a repeated attempt to regain structural stability.

This discussion indicates that presence of alternative states of equilibrium and alternative paths of evolution is not a desirable trait in a system. The above could result from inevitable bifurcations in the system which, in the analyzed case, implies the segmentation of property prices (variation that accounts for the specific features of property). Further work is needed to address this issue.
Regardless of possible evolution scenarios, the above analysis confirms our assumptions that the evolution of real estate markets combines two mutually intertwined processes: long-term evolution, which takes place mostly in the area of system stability, and sudden changes (short-term) which are difficult to predict, are initiated in the area of the pointed tip and take place in the area of instability. A new sudden change can occur as long as the path is situated in the cusp (fold) area. The path's emergence from the cusp area implies that a new evolutionary path was found by the market after a period of rapid growth and that a stormy phase is sometimes followed by a period of smooth growth.

\section{Conclusions}

The real estate market as an essential part of the economic system has a significant impact on each field of human activity. Our results broadly support the idea that the strong fluctuations in the real estate prices observed in many countries are not just disruptions of trends or cycles but are an essential part of the market, which destabilized by changes in the macroeconomic situation - seeks a new state of equilibrium through quasi-discrete changes in prices. It means that real estate market instability can generate a fluctuating, discontinuous change in real estate prices. The real estate market is a dynamical system in which periods of sudden fluctuations in prices can be defined as critical moments in its evolution. In such moments, the ability to develop further inside the current model is exhausted and a search for a new, alternative path of development commences.

The results of the study validate the main hypothesis which postulates the presence of instability intervals during the evolution of real estate markets. Unlike smooth, long-term evolution over the equilibrium surface, the short-term catastrophic influence of control parameters on the system gives rise to discontinuous transition, i.e. sudden changes between different equilibrium states of the system.

It seems that the moment of change cannot be predicted and changes are generally signaled with a certain delay after data collected in a broader time interval have been analyzed. Catastrophe theory can be a useful tool for developing indicators of a catastrophe. The analyzed system's current status and probable development scenario, which will take the system in the direction of structural instability or structural stability, can be illustrated with a graphic representation of the evolutionary path. Hence provide predictive results which allow for more accurate economic analyses, results, insurance and long term financial gains.

The presented research leads to another important conclusion that contemporary local real estate markets are increasingly sensitive to changes in international financial markets. A similar effect of global factors on local economic relations is provided by wikinomics, especially in the area of public administration [62]. 


\section{References}

[1] J.A. Schumpeter, The Theory of Economic Develop ment: An Inquiry into Profits, Capital, Credit, Interest, and the Business Cycle, Transaction Publishers, New Brunswick 2004.

[2] R. Domański, Evolutionary Spatial Economy, Wydawnictwo Uniwersytetu Ekonomicznego w Poznaniu, Poznań 2012 (in Polish).

[3] A. Jakimowicz, Int. J. Nonlin. Sci. Num. Simul. 17, 1 (2016).

[4] E.D. Beinhocker, The Origin of Wealth: Evolution, Complexity, and the Radical Remaking of Economics, Harvard Business School Press, Boston 2006.

[5] D. Colander, J. Hist. Economic Thought 22, 127 (2000).

[6] Y.-C. Lu, Singularity Theory and an Introduction to Catastrophe Theory, Springer-Verlag, New York 1976.

[7] M. Montagnana, F. Prizzon, F. Zorzi, Papers Regional Sci. Assoc. 69, 153 (1989).

[8] X.J. Ge, G. Runeson, A dynamic model of housing markets and house prices, Proceedings of the Australasian Universities Building Educators Association (AUBEA), University of Technology Sydney, 2006, pp. 1-18. Retrieved April 12, 2017.

[9] X.J. Ge, G. Runeson, A.Y.T. Leung, C.A. Tang, in: Proc. 2006 HKU-NUS Symp. on Real Estate Research, Hong Kong University, 2006, p. 229. Retrieved April 14, 2017.

[10] I. Barens, P. Flaschel, F. Hartmann, A. Röthig, Europ. J. Econom. Economic Policies Intervent. 7, 361 (2010).

[11] D. Yang, D. Mu, M. Yao, in: Proc. 2009 Int. Conf. on Management and Service Science, Wuhan 2009, p. 1.

[12] A. Pleten, in: Market Risk and Financial Markets Modeling, Eds. D. Sornette, S. Ivliev, H. Woodard, Springer-Verlag, Berlin 2012, p. 201.

[13] D. Wesselbaum, Scott. J. Politic. Econ. 64, 376 (2017).

[14] J. Barunik, M. Vosvrda, J. Econ. Dyn. Control 33, 1824 (2009)

[15] J. Barunik, J. Kukacka, Quantitat. Finance 15, 959 (2015).

[16] J. Wang, Ph.D. Thesis, University of Amsterdam, Amsterdam 2015. Retrieved April 24, 2017.

[17] C. Diks, J. Wang, J. Econ. Dyn. Control 69, 68 (2016).

[18] M. Bełej, Real Estate Manage. Valuat. 21, 51 (2013).

[19] D. DiPasquale, W.C. Wheaton, Urban Economics and Real Estate Markets, Prentice-Hall, Englewood Cliffs 1996.

[20] N. Carn, J. Rabianski, R. Racster, M. Seldin, Real Estate Market Analysis: Techniques and Applications, Prentice-Hall, Englewood Cliffs 1988.

[21] P. Hilbers, Q. Lei, L. Zacho, Real Estate Market Developments and Financial Sector Soundness, International Monetary Fund, IMF Working Paper No. WP/01/129, September 2001. Retrieved April 25, 2017.

[22] G.A. Tobin, B.E. Montz, Soc. Sci. J. 25, 167 (1988).
[23] I. Foryś, Social and Economic Determinants of the Housing Market Development in Poland: A Quantification, Wydawnictwo Naukowe Uniwersytetu Szczecińskiego, Szczecin 2011 (in Polish).

[24] D. Venclauskiene, V. Snieska, Econ. Manage. 14, 1026 (2009) Retrieved April 20, 2017.

[25] R. Gerlach, P. Wilson, R. Zurbruegg, J. Int. Money Finance 25, 974 (2006).

[26] J.M. Quigley, Int. Real Estate Rev. 2, 1 (1999). Retrieved April 5, 2017.

[27] D. Sornette, R. Woodard, in: Econophysics Approaches to Large-Scale Business Data and Financial Crisis, Eds. M. Takayasu, T. Watanabe, H. Takayasu, Springer Science + Business Media, Tokyo 2010, p. 101.

[28] Structural Factors in the European Union Housing Markets, European Central Bank, Frankfurt am Main 2003. Retrieved April 10, 2017.

[29] M. Gell-Mann, The Quark and the Jaguar: Adventures in the Simple and the Complex, Holt and Co., New York 1994.

[30] A. Jakimowicz, From Keynes to Chaos Theory. Evolution of Business Cycle Theories, series: Wspótczesna Ekonomia, Wydawnictwo Naukowe PWN, Warszawa 2012 (in Polish).

[31] Fuzzy Sets. Pattern Recognition. Catastrophe Theory. Selection of Texts, Eds. M. Cieślak, A. Smoluk, Państwowe Wydawnictwo Naukowe, Warszawa 1988 (in Polish).

[32] L. Campbell, W. Garnett, The Life of James Clerk Maxwell: With a Selection from His Correspondence and Occasional Writings and a Sketch of His Contributions to Science, Cambridge University Press, Cambridge 2010, Ch. XIV, p. 440.

[33] K.J. Arrow, Collected Papers of Kenneth J. Arrow, Vol. 2, General Equilibrium, The Belknap Press of Harvard University Press, Cambridge 1983

[34] R. Gilmore, in: Encyclopedia of Applied Physics, Vol. 3, Calibration and Maintenance of Test and Measuring Equipment to Collective Phenomena in Solids, Ed. G.L. Trigg, Wiley-VCH, New York 1992, p. 85.

[35] R. Thom, Paraboles et catastrophes. Entretiens sur les mathématiques, la science et la philosophie realisés par Giulio Giorello et Simona Morini (Parables, Parabolas and Catastrophes: Conversations on Mathematics, Science and Philosophy. Interviews and Notes by Giulio Giorello and Simona Morini), Flammarion, Paris 1983 (in French).

[36] R. Thom, Structural Stability and Morphogenesis: An Outline of a General Theory of Models, W.A. Benjamin, London 1975.

[37] A. Okniński, Catastrophe Theory, Polish Scientific Publishers PWN, Warszawa 1992.

[38] L. Cobb, S. Zacks, J. Am. Statist. Assoc. 80, 793 (1985).

[39] J. Casti, H. Swain, in: Optimization Techniques Modeling and Optimization in the Service of Man, Part 1, Ed. J. Cea, Springer-Verlag, Berlin 1976, p. 388.

[40] J.C. Amson, Environm. Plan. B Urban Analyt. City Sci. 2, 177 (1975). 
[41] A.G. Wilson, Catastrophe Theory and Bifurcation: Applications to Urban and Regional Systems, Routledge, New York 2011.

[42] H.J. Sussmann, R.S. Zahler, Behavior. Sci. 23, 383 (1978).

[43] S.J. Guastello, Behavior. Sci. 26, 63 (1981).

[44] P.A.I. Hartelman, H.L.J. van der Maas, P.C.M. Molenaar, Brit. J. Developm. Psychol. 16, 97 (1998).

[45] D.J. Wales, Science 293, 2067 (2001).

[46] L. Fuhua, W. Huanmin, Acta Mech. Sin. 1, 185 (1985).

[47] E.C. Zeeman, J. Math. Econ. 1, 39 (1974).

[48] E.C. Zeeman, Sci. Am. 234, 65 (1976).

[49] J.B. Rosser, Jr., From Catastrophe to Chaos: A General Theory of Economic Discontinuities, Vol. I, Mathematics, Microeconomics, Macroeconomics, and Finance, 2nd ed., Springer Science + Business Media, New York 2000.

[50] J.B. Rosser, Jr., J. Econ. Dyn. Control 31, 3255 (2007).

[51] A. Jakimowicz, Acta Phys. Pol. A 117, 640 (2010).

[52] W. Dou, S. Ghose, J. Busin. Res. 59, 838 (2006).

[53] H.R. Varian, Economic Inquiry 17, 14 (1979).
[54] L. Cobb, B. Watson, Math. Modell. 1, 311 (1980).

[55] P.A.I. Hartelman, Ph.D. Thesis, University of Amsterdam, Amsterdam 1997.

[56] R.P.P.P. Grasman, H.L.J. van der Maas, E.-J. Wagenmakers, J. Statist. Software 32, 1 (2009).

[57] L. Cobb, An Introduction to Cusp Surface Analysis, 1998. Retrieved May 16, 2017.

[58] E.-J. Wagenmakers, P.C.M. Molenaar, R.P.P.P. Grasman, P.A.I. Hartelman, H.L.J. van der Maas, Physica D 211, 263 (2005)

[59] D.J.A. Trotman, E.C. Zeeman, in: Structural Stability, the Theory of Catastrophes, and Applications in the Sciences, Ed. P. Hilton, Springer-Verlag, Berlin 1976, p. 263.

[60] J.B. Rosser, Jr., Implications for Teaching Macroeconomics of Complex Dynamics, Department of Economics, James Madison University, Harrisonburg 1999. Retrieved May 4, 2017.

[61] Cusp-Catastrophe Model Fitting Using Maximum Likelihood, 2015; Retrieved May 25, 2017.

[62] A. Jakimowicz, D. Rzeczkowski, Acta Phys. Pol. A 129, 1011 (2016). 